Pakistan Journal of Humanities and Social Sciences

April - June 2018, Volume 6, No. 2, Pages 160 - 168

\title{
Inflation dynamics analysis in selected MENA countries
}

\author{
Tarek Kacemi ${ }^{1}$, Sallahuddin Hassan ${ }^{2}$ \\ ${ }^{1} \mathrm{PhD}$ Scholar, School of Economics, Finance \& Banking, Universiti Utara Malaysia \\ ${ }^{2}$ Associate Professor, School of Economics, Finance \& Banking, Universiti Utara Malaysia \\ Email: tarek.king39@gmail.com
}

\begin{abstract}
The current paper analyses the new Keynesian Phillips curve (NKPC) in the context of selected MENA countries over the 1990-2016 period. This study has used Pooled Mean Group (PMG) and Fully Modified Ordinary Least Square (FMOLS) estimation methods for the empirical analysis. For the dynamic heterogeneous panels, PMG developed by Pesaran et al. (1999) is the most suitable technique. The outcomes by FMOLS asserted that inflation and unemployment are unrelated in the long run, corroborating the long run Philips Curve theory. While, the empirical outcomes obtained by PMG indicate negative linkage between unemployment and inflation in the long run. Nevertheless, the notion of the tradeoff between the inflation and unemployment that expressed by a short-run Phillips curve is not observed in the selected MENA countries. The findings of this study corroborate the hybrid version of NKPC. Moreover, it establishes of the study suggest that the dynamic inflation can be used as a HNKPC model for understanding the inflation behavior in selected MENA countries.
\end{abstract}

Keywords: Inflation, Phillips curve, FMOLS, PMG

\section{Introduction}

In macroeconomics literature, the short-run inflation dynamics held the central concern. The debate concerning this issue is still contentious and possesses scarce evidences in the literature, despite the extensive investigation over decades. Previously, the conventional (wage) Phillips curve (PC) during the 1970s, asserted a firm trade-off concerning the (wage) inflation and economic activity (unemployment rate). Thus, lead to the term of persistence that had been considered as an acknowledged feature of the inflation process in general. Although, this specification of the PC is a success yet, its parameters' estimation remained a serious issue of concern. These are related to the choice of variables to be used for the validation of the PC equation and to the estimation method. 
Pakistan Journal of Humanities and Social Sciences, 6(2), 2018

The concept of "New Keynesian Phillips curve (NKPC)" emerged during the 1990s. Its proponents criticized the traditional Philips Curve for its backward-looking nature which remained nonstable across policy regimes (critique of Lucas), not being consistent with the rational expectations, additionally, over prediction of inflation in the context of industrialized nations over the previous few decades. Moreover, micro economic theory provides the basis for NKPC. Moreover, by following the seminal contribution of Gali and Gertler (1999), it is achieving popularity, as a consequence of its robustness to the critique of Lucas. Additionally, the NKPC structural parameters are not influenced by any change in policy, with assumption of nominal inflexibilities in economic agents' behavior.

Furthermore, the NKPC models followed a firm version elucidating the development of inflation by an amalgamation, linking exclusively its anticipated level and a measure of marginal cost as the NKPC emerges from monopolistic competition framework and price inelasticity. The NKPC associates the contemporary price inflation to the inflation appeared to be in the future as perceived by the economic agents. However, Ben Ali (2013) criticized this purely forward-looking version for not being verified by any empirical investigation yet, particularly for the European and U.S. data which have revealed its limitations during the data generator process. As a result, the researchers continue to explain some persistence in the inflation dynamics by introducing the lagged values of inflation in the supposed hybrid version of Phillips curve.

This paper examines the HNKPC in the context of the selected MENA countries. Further, FMOLS and the PMG related issues have also been discussed. In the MENA countries, the government has expressed its interest in reducing its double-digit inflation. Therefore, it seems possible to endeavor to examine the dynamics of inflation in relation to a HNKPC.

Moreover, the rest of the current study is arranged as follows: the theoretical framework of the NKPC and HNKPC. Next, follows by methodology that presents the model specification estimation method and results and discussion for the selected MENA countries. The final section provides the concluding remarks.

\section{Literature Review}

The baseline dynamic inflation has undergone a theoretical and empirical evolution in the literature. The incompleteness of the pure forward-looking NKPC leads to the studies of the HNKPC. Thus, following the superiority of HNKPC dynamic inflation version over NKPC, the hybrid NKPC has also commenced a new empirical discussion concerning the 
vision of economic agents to anticipate either it is forward-looking or it is backward-looking in the process of economic choices (Galí \& Gertler, 1999; Rudd \& Whelan, 2005). In this perspective, the quantitative magnitude of the coefficients of both the lagged and anticipated inflation are also assumed to be essential, other than the statistical significance of the parameters. Moreover, Nakahira (2015) argued that the HNKPC is likely to commence a discussion regarding the monetary policy to include the backward-looking perspective in addition to the forward-looking perspective in exploring the inflation persistence.

Studies that verified the empirical validity of the NKPC model of HNKPC were Ramos-Francia and Torres (2008), Mardaneh (2012), Ben Ali (2013), Yesilyurt and Elhorst (2014), and recently Kobbi and Gabsi (2017). Ramos-Francia and Torres (2008) and recently Kobbi and Gabsi (2017) found evidence of both backwards and forward-looking components in Mexican and Tunisia. Ramos-Francia and Torres (2008) labelled the short-run dynamics of inflation in the Mexican economy from 1992-2007 with both backwards and forward-looking components.In addition,, Kobbi and Gabsi (2017) has indicated that the forward-looking behavior is as important as backward-looking in determining inflation in Tunisia during 1993-2012 with Logistic Smooth Transition Regression model. As the inflation rate increases and reaches to a certain threshold level, its response to the output gap inclines to be significant.

Study in support of backwards looking behaviour to be more or equally essential than forwarding looking behaviour is Yesilyurt and Elhorst (2014) that used Turkey data from 67 provinces during 1987-2001. Meanwhile, Ben Ali (2013) and Mardaneh (2012) found evidence of forward-looking component in Tunisia and Iran. Ben Ali (2013) is in support of the hybrid type NKPC, with greater portion of the forward-looking factor in case of Tunisia, employing the generalized method of moments during 1991Q1 to 2007Q2. Also, Mardaneh (2012) with GMM technique found forward-looking behavior gains ground while the backward-looking behavior becomes less important in Iran during the period of 1976Q2010Q.

In the pertaining literature, fewer empirical studies have examined the panel version of the Phillips curve particularly in case of the selected MENA countries. The study of Agénor and Bayraktar (2010) is one of those limited studies, which have provided empirical outcomes regarding the Phillips curve in context of the eight developing countries over the 1979-2006 period. They have proposed a modified version of the HNKPC, not concluding a major weight of the forward-looking factor in the model as argued by most of the studies. 
Pakistan Journal of Humanities and Social Sciences, 6(2), 2018

Consequently, this paper empirically investigates the relationship and the effects of inflation dynamic in the selected MENA countries from 1990 to 2016.

\section{Methodology}

The current study employs a panel-data approach covering selected nine MENA countries over the period 1990-2016. This modification is recognized as the HNKPC. It considers that for price determination there exist subgroup of companies, which follow the backward-looking rule-of-thumb, whereas the other companies operate in a forward-looking way. The HNKPC, on theoretical basis, is an attractive specification as the expected inflation and lagged inflation becomes positive.

Further, this study employs the variables as used in the literature namely population growth rate which is a measures the labor force growth and is indicated by pop. Similarly, trade openness is measured as the exports plus imports divided by GDP, employed as a proxy variable for the significance of international dynamics in affecting the economic activity.

However, some researchers such as Gali and Gertler (1999) noticed that NKPC failed to adequately measure the empirical dependence of inflation over its own lagged values. They then developed Hybrid New-Keynesian Phillips Curve (HNKPC) which is a developed version of the NKPC model. In this model, lagged inflation $\left(\pi_{t-1}\right)$ is incorporated. The rationale is to examine the expected future inflation and lagged inflation $\left(\pi_{t-1}\right)$. Thus, the HNKPC is expressed in Equation [1] for representing inflation dynamic model.

$$
\pi_{t}=\alpha \pi_{t-1}+\beta \mathrm{E}_{t} \pi_{t+1}+\gamma x_{t}
$$

Where $\alpha, \beta$ and $\gamma$ are the unknown parameters. This model allows inflation to be determined either the observed inflation autocorrelation emerges from the backward-looking behavior ( $\beta=0$ ) or from the forward-looking behavior $(\alpha=0)$ as measured by inflation lags.

The model is the extension of the objectives in this study in Equation [1] as dynamic inflation and the structure equation for the dynamic model can be written as Equation [2]:

$$
I N F_{i t}=\alpha I N F_{i, t-1}+\beta \mathrm{E}_{t} I N F_{i, t+1}+\gamma U E M_{i t}+E X R_{i t}+G D P P C_{i t}+P R_{i t}+M s_{i t}+\varepsilon_{i t}
$$

Where $\alpha, \beta$ and $\gamma$ are unknown parameters. This model assumes inflation to be determined whether the observed inflation autocorrelation emerges from the backwardlooking behavior ( $\alpha=0$ ) or from the forward-looking behavior $(\beta=0)$ as measured by the inflation lags. 


\section{Result and Discussion}

The section provides the descriptive analysis of the panel data for selected MENA countries in Table 1. The analysis includes descriptive statistics and correlation coefficients of key variables of the research. These are present in the following tables.

Table 1: Descriptive Statistics for Panel Data

\begin{tabular}{|c|c|c|c|c|}
\hline Variables & Mean & Standard Deviation & Maximum & Minimum \\
\hline$I N F$ & 14.555 & 23.300 & 132.824 & -1.348 \\
\hline$E X R$ & 928.374 & 3866.742 & 30914.85 & 0.003 \\
\hline$G D P C$ & 2.134 & 3.594 & 12.820 & -7.890 \\
\hline$M S$ & 20.665 & 22.349 & 144.800 & -2.040 \\
\hline$P R$ & 2.0432 & 0.968 & 5.560 & 0.760 \\
\hline$U E M$ & 12.559 & 4.825 & 29.790 & 4.300 \\
\hline
\end{tabular}

The included variables are $I N F$, the dependent variable in all four models, whereas, $E X R, G D P C, M S, P R$, and $U E M$ are the independent variables in the model. Looking at the value of the mean and standard deviation, it can be observed that the standard deviation of $P R$ and $U E M$ is lower than the mean for the observation, implying the observations are not far away from their mean. Meanwhile, a higher dispersion is found for the variables INF, EXR, $G D P C$, and $M S$, as their standard deviations are much higher than their respective means.

The outcomes of the correlation test between the dependent variable and independent variables proved to be essential in pre-estimation analysis regarding the potential linkage as recommended by theories. The study conducts correlation analysis to see the magnitude and direction of the association between regressors and regress and. The correlation analysis is performed among variables of interest for the selected MENA countries to observe the mutual association among variables and the results are presented in below Table

Table 2: Correlation Analysis for Panel Data

\begin{tabular}{|c|c|c|c|c|c|c|}
\hline Correlation & $\boldsymbol{I N F}$ & $\boldsymbol{E X R}$ & $\boldsymbol{G D P C}$ & $\boldsymbol{M S}$ & $\boldsymbol{P R}$ & $\boldsymbol{U E M}$ \\
\hline $\boldsymbol{I N \boldsymbol { F }}$ & 1.000 & & & & & \\
\hline $\boldsymbol{E} \boldsymbol{R} \boldsymbol{R}$ & 0.033 & 1.000 & & & & \\
\hline $\boldsymbol{G D P C}$ & -0.023 & -0.043 & 1.000 & & & \\
\hline $\boldsymbol{M S}$ & $0.849^{*}$ & 0.078 & 0.007 & 1.000 & & \\
\hline $\boldsymbol{P R}$ & 0.082 & $-0.202^{*}$ & $-0.168^{*}$ & -0.022 & 1.000 & \\
\hline $\boldsymbol{U E M}$ & -0.028 & -0.053 & -0.002 & -0.068 & -0.008 & 1.000 \\
\hline
\end{tabular}

Note: * shows the rejection of null hypothesis at 5 percent level of significance, respectively.

The Table 2 shows a strong positive correlation between $M S$ and INF as the value of correlation coefficient is also 0.849 . Yet, there exists weak negative correlation between $P R$ and $E X R$, and also $P R$ and GDPC as it can be observed by the value of correlation coefficient 
Pakistan Journal of Humanities and Social Sciences, 6(2), 2018

which is 0.202 and 0.168 , respectively. PMG is primarily a long-run analysis, and more attention is shifted towards the long-run coefficients.

Table 3: PMG the Long-Run Coefficients Estimates for the selected MENA Countries

\begin{tabular}{|c|c|c|c|c|}
\hline Variable & Coefficient & Std. Error & t-Statistic & Prob. \\
\hline $\boldsymbol{U E M}$ & -0.431 & 0.168 & -2.567 & $0.011^{*}$ \\
\hline $\boldsymbol{E X \boldsymbol { R }}$ & -0.000 & 0.000 & -0.378 & 0.706 \\
\hline $\boldsymbol{G D P C}$ & -0.256 & 0.340 & -0.753 & 0.453 \\
\hline $\boldsymbol{M} \boldsymbol{S}$ & 0.855 & 0.039 & 21.696 & $0.000^{*}$ \\
\hline $\boldsymbol{P} \boldsymbol{R}$ & 0.020 & 0.820 & 0.025 & 0.980 \\
\hline
\end{tabular}

Note: * indicates the rejection of null hypothesis at 5 percent level of significance.

Here, in Table 3 the long-run estimates the coefficients of the UEM shows negative effect on INF. This findings corroborate the theory of PC theory. The coefficients of the money supply show positive effect on $I N F$. The result of this study is also in line with the theory.

Table 4: PMG the Short-Run Coefficients Estimates for the selected MENA Countries

\begin{tabular}{|c|c|c|c|c|}
\hline Variable & Coefficient & Std. Error & t-Statistic & Prob. \\
\hline $\boldsymbol{E C T}$ & -0.328 & 0.066 & -5.003 & $0.000^{*}$ \\
\hline $\boldsymbol{D}(\boldsymbol{U} \boldsymbol{E M})$ & -0.135 & 1.113 & -1.172 & 0.243 \\
\hline $\boldsymbol{D}(\boldsymbol{E} \boldsymbol{X} \boldsymbol{R})$ & 49.184 & 34.182 & 1.439 & 0.152 \\
\hline $\boldsymbol{D}(\boldsymbol{G D P P C})$ & 0.362 & 0.280 & 1.294 & 0.197 \\
\hline $\boldsymbol{D}(\boldsymbol{M S})$ & -0.182 & 0.063 & -2.914 & $0.004^{*}$ \\
\hline $\boldsymbol{D}(\boldsymbol{P R})$ & 4.931 & 2.800 & 1.761 & $0.080^{* *}$ \\
\hline
\end{tabular}

Note: * indicates the rejection of null hypothesis at 5 percent level of significance.

Table 4 presents the short-run estimates of the coefficients for the selected MENA countries. The coefficient of the cointegration equation goes with the usual underlying assumption to validate the convergence to long run equilibrium. The ECT is negative, indicating significance level at 5 percent and is less than unity.

The coefficient attached with this term explains that, the rate of convergence towards long run of equilibrium is 32.8 percent in the annually. Moreover, all the coefficients of all the variables like EXR and GDPC are insignificant at any level of the permissible levels of significance except $M S$ and $P R$ which is significant at 5 percent and 10 percent level of significance.

From the PMG estimation, the notion of the trade-off between the inflation and unemployment that is shown by a short-run Phillips curve is not observed in the selected MENA countries as there no evidence is found between the variables in the short run. 
Table 5: FMOLS Regression result

\begin{tabular}{|c|c|c|c|c|}
\hline Variable & Coefficient & Std. Error & t-Statistic & Prob. \\
\hline $\boldsymbol{U E M}$ & -0.034 & 0.040 & -0.854 & 0.394 \\
\hline $\boldsymbol{E} \boldsymbol{X} \boldsymbol{C}$ & -6.260 & 7.720 & -0.081 & 0.935 \\
\hline $\boldsymbol{G P \boldsymbol { P }}$ & -0.136 & 0.075 & -1.804 & $0.073^{*} *$ \\
\hline $\boldsymbol{P R}$ & -0.073 & 0.223 & -0.326 & 0.744 \\
\hline $\boldsymbol{M S}$ & 0.130 & 0.022 & 5.830 & $0.000^{*}$ \\
\hline $\boldsymbol{I N F ( - 1 )}$ & 0.382 & 0.023 & 16.371 & $0.000^{*}$ \\
\hline $\boldsymbol{I N F ( 1 )}$ & 0.482 & 0.026 & 18.012 & $0.000^{*}$ \\
\hline $\boldsymbol{R}$-squared & 0.865 & \multicolumn{2}{|c|}{ Adjusted $\boldsymbol{R}$-squared } & 0.867 \\
\hline
\end{tabular}

Note: * indicates the rejection of null hypothesis at 5 percent level of significance.

The coefficient of the $M S$ appeared to be positive and is significant at $1 \%$, which demonstrates that an increase in $M S$ stimulates the positive effect of $I N F$ in the selected MENA countries. In addition, GDPC is also positive and significant at $5 \%$.

$U E M$ is not significant to inflation in the long run. Inflation and unemployment are not correlated in the long run, so the long-run Phillips curve is a vertical line at the natural rate of unemployment, which is in line with the theory.

The coefficient of the both the lagged and forward INF is positive and significant at 5 $\%$. However, coefficient of forward $I N F$ is larger than lagged $I N F$ as in 48.2 percent and 38.2 percent, respectively. Thus, the forward INF is more dominant that the lagged INF in the selected MENA countries.

Moreover, the empirical outcomes of this study observed the HNKPC for successfully explaining the inflation dynamic in the selected MENA countries. The backward-looking parameter has statistically been concluded to be significant in this study. Additionally, the results support a major weight of the forward-looking factor in the model. Furthermore, this study observed the lagged and lead inflation rate variables to be significant and assert overall a positive influence on the present inflation. Likewise, this study is also in line with Agénor and Bayraktar (2010) that concluded the same outcomes in case of the eight developing economies.

\section{Concluding Remarks}

The core objective of this study was examining the validity of the HNKPC in the context of MENA data. The outcomes employing the PMG and FMOLS recommend that the empirical confirmation of this curve in context of the selected MENA economies is that similarity of the finding money supply is found to be positively significant to inflation in the long run. However, the difference between two estimations is that the finding of unemployment is found to be negatively significant to inflation in the PMG estimation, while 
unemployment is not significant to inflation in the long run in FMOLS. Inflation, which is unrelated to the unemployment, proved the evidence PC theory that in the long run, PC is a vertical line at the natural rate of unemployment. Moreover, this study evidently revealed that no evidence has been found between inflation and unemployment in the short run as notion by the PC trade-off.

Further, the outcomes of the current study has observed HNKPC in elucidating the inflation dynamic in the selected MENA countries as this study concluded a major weight of the forward-looking factor in the MENA countries. Additionally, this study empirically observed the lagged and the lead inflation rate variables to be significant and to assert overall a positive influence on the current inflation. Policy implications of the expected inflation are highly affect inflation, explaining high inflation persistence. Thus, one of the major objectives of the monetary policy should be to control inflation expectations in selected MENA countries because controlling expectations are the step in managing inflation. 


\section{References}

Agénor, P. R., \& Bayraktar, N. (2010). Contracting models of the Phillips curve empirical estimates for middle-income countries. Journal of Macroeconomics, 32(2), 555-570.

Ben Ali, S. (2013). Estimating the New Keynesian Phillips Curve for Tunisia: Empirical Issues. Middle East Development Journal, 5(3), 1350016-1.

Gal1, J., \& Gertler, M. (1999). Inflation dynamics: A structural econometric analysis. Journal of Monetary Economics, 44(2), 195-222.

Kobbi, I., \& Gabsi, F. B. (2017). The nonlinearity of the new Keynesian Phillips curve: The Case of Tunisia. Economies, 5(3), 24-28.

Mardaneh, S. (2012). How Do Oil Shocks Affect theStructural Stability of Hybrid New Keynesian Phillips Curve? (No. 12/20). University of Leicester Working Paper. Available at: www.le.ac.uk/ec/research/RePEc/lec/leecon/dp12-20.pdf

Nakahira, K. (2015). The Hybrid New Keynesian Phillips Curve and Firm-Level Inflation Expectations in Japan. International Journal of Economic Behavior and Organization, 3(2-1), 61-72.

Pesaran, M. H., Shin, Y., \& Smith, R. P. (1999). Pooled mean group estimation of dynamic heterogeneous panels. Journal of the American Statistical Association, 94(446), 621634.

Ramos-Francia, M., \& Torres, A. (2008). Inflation dynamics in Mexico: a characterization using the new Phillips curve. The North American Journal of Economics and Finance, 19(3), 274-289.

Rudd, J., \& Whelan, K. (2005). New tests of the new-Keynesian Phillips curve. Journal of Monetary Economics, 52(6), 1167-1181.

Yesilyurt, F., \& Elhorst, J. P. (2014). A regional analysis of inflation dynamics in Turkey. The Annals of regional science, 52(1), 1-17. 